\title{
Second Language Use as a Threshold Concept: Reconceptualising Language Learning Journeys
}

\author{
Luke Carson ${ }^{1, *}$ \\ ${ }^{1}$ Faculty of International Studies, Hiroshima City University, 3-4-1 Ozuka higashi, \\ Asaminamiku, Hiroshima, 731-3194, Japan \\ *Correspondence: Faculty of International Studies, Hiroshima City University, 3-4-1 Ozuka \\ higashi, Asaminamiku, Hiroshima, 731-3194, Japan. E-mail: carsonl@intl.hiroshima-cu.ac.jp
}

Received: April 11, 2017 Accepted: May 12, 2017 Published: May 26, 2017

doi:10.5296/ije.v9i2.11315 URL: https://doi.org/10.5296/ije.v9i2.11315

\begin{abstract}
While the word 'threshold' is used in language learning frameworks, a threshold concept from a learning theory perspective refers to a "transformed way of understanding" (Meyer \& Land, 2006), that brings with it an ontological shift in the minds of learners. This paper discusses the possibility that the jump from learning a language to learning and using a language in certain contexts may be such a threshold concept in certain EFL contexts. This discussion follows a mapping of the characteristics of threshold concepts onto the act of learning a language for the purpose of communicative competence. This understanding posits that active communication in a foreign language can be both simultaneously more difficult and more meaningful than educators may always recognise. Drawing on what learning theory has discovered about 'troublesome' learning, the discussion provides a reframing of some learner journeys to becoming communicators. This paper discusses this issue from three perspectives. Firstly, it outlines what learning theory and theorists have discovered about threshold concepts. Secondly, it puts forward the notion that in some university contexts (with specific reference to Japanese university EFL contexts), active communication in a second language may be a threshold concept for students who are still second language 'communication novices'. Finally, it discusses some of the curricular, instructional and assessment design implications of this position.
\end{abstract}

Keywords: active communication, context-specific, culture, EFL, language learning, threshold concept, troublesome knowledge 


\section{Introduction}

"A threshold concept can be considered as akin to a portal, opening up a new and previously inaccessible way of thinking about something. It represents a transformed way of understanding, or interpreting, or viewing something without which the learner cannot progress. As a consequence of comprehending a threshold concept there may thus be a transformed internal view of subject matter, subject landscape, or even worldview. This transformation may be sudden or it may be protracted over a considerable period, with the transition to understanding proving troublesome" (Meyer \& Land, 2006, p.3). In certain EFL contexts, moving from passive learning of the parts of a language to using it in an authentic manner and context undeniably brings with it affective issues (Arnold, 1999). Yet it may also bring with it cognitive issues, such as the learners understanding of their relationship with the language in question.

\subsection{Threshold Concepts in Learning}

In any learning discipline, students can experience learning difficulties with different aspects of the content or in the application of content knowledge. However, what if there are specific content or action points in a learning discipline that are highly 'troublesome' (Perkins, 2012)? Learning theorists in recent years are paying more attention to certain points of difficulty in a curriculum, that may also be "key points necessary for progress" (Land, 2011) - what have now been called threshold concepts. In order to illustrate what threshold concepts in learning are, and how impactful they are on the learning process, two first person account examples are given below.

"When I was an undergraduate student studying sociology, we had to learn and use a statistical analysis package called SPSS. Having never taken a statistics course, it was all gobbledygook, and gobbledygook that built upon itself, so each class became more and more impenetrable. How social ideas and practices, which I could understand in and of themselves, could be interpreted or investigated in this way was beyond me. Thankfully, due to the group work nature of the course, and some kind senior students, I somehow manage to scrape through the course without getting it at all, thankful that I had no future intention or need for this knowledge again. Fast forward a decade, and I was, surprisingly, a young career academic with a cold sweat-inducing fear of quantitative research.........."

"Opportunity cost... when I finally got my mind around that... which took some time... the concept jumped off the economics textbook page and into my reality - the world changed. All the other class content started to make sense as I could place it around this idea, and also take this idea beyond the idea of economic production, to behavioural economics, to my own choices...

When learners 'get' a threshold concept, there is an ontological shift - the meaning something holds for them changes, impacting their worldview and understanding of the other of things. However, when they do not 'get it', they remain in what Land has termed 'liminality' or a state of mimicry (2011). This can be exemplified through traditional second language learning activities. Imagine a language classroom, where students are asked to 
perform role-plays in the target language. Likely, the role-play will have a communicative purpose. Yet for the pair of learners who do not yet understand foreign languages as communicative tools, it is possible for them to participate in this task while remaining in a state of mimicry. They can construct sentences, questions and answers from model textbook examples, perform them and finish. For them, the new language may simply be an object that is occasionally "performed" (Smith-Christmas, 2017, p.32). If this task is graded, they can possibly receive a good grade for it. Does this mean that they have internalized the transferable purpose of this task, or are they even communicating? Not necessarily. The ontological shift required is not an automatic or easy process for all. If threshold concepts exist in a discipline, then in order to design and facilitate effective learning, learning and teaching reconceptualisations many be needed. If something is troublesome to learn, it will likely be "in turn challenging to teach" (O'Brien, 2008). Instructional and pedagogic revisions may need to be identified and addressed.

Opportunity cost in economics and statistical analysis of social phenomenon are just two examples of possible threshold concepts. To date, there has not been much research into these concepts in second language learning, though Orsini-Jones (2008) has identified some grammatical structures as troublesome - morphemes, phrases and clauses. But what do these concepts, from different disciplines, have in common? In their research, Meyer \& Land (2013) have identified the following 5 characteristics of threshold concepts.

Table 1. Characteristics of Threshold Concepts

\begin{tabular}{|c|c|}
\hline Transformative & $\begin{array}{l}\text { once it is understood it leads to a much improved } \\
\text { understanding and perception of the subject. }\end{array}$ \\
\hline Probably irreversible & $\begin{array}{l}\text { the concept and ensuing change in perspective is unlikely to } \\
\text { be quickly or easily forgotten. }\end{array}$ \\
\hline Integrative & it leads to an integration of ideas within the subject. \\
\hline Expansive & $\begin{array}{l}\text { it has boundaries with other threshold concepts, and in } \\
\text { certain instances with other disciplines. }\end{array}$ \\
\hline Troublesome & $\begin{array}{l}\text { students have difficulty grasping or understanding the } \\
\text { concept }\end{array}$ \\
\hline
\end{tabular}

(Meyer \& Land, 2013).

\subsection{Threshold Levels in Language Learning Research}

The above definition and examples differ from the meaning of the term 'threshold level' that is used in existing language learning frameworks and research. For example in the Common European Framework of Reference for Languages (CEFR), threshold levels are used to "describe language learners abilities in terms of speaking reading, listening and writing at six different levels" (Cambridge, 2011). The six levels are outlined in the table that follows. 
Table 2. CEFR Threshold Levels

\begin{tabular}{lll}
\hline C2 & Mastery & Proficient User \\
C1 & Efficient Operational Proficiency & \\
B2 & Vantage & Independent User \\
B1 & Threshold & \\
A2 & Waystage & Basic User \\
A1 & Breakthrough & \\
\hline
\end{tabular}

(Cambridge, 2011).

The CEFR has been a very positive, influential development in second language teaching as it focuses very directly on language use, in line with the movement in language teaching towards a communicative approach. It is used to both describe learners language competency levels and by pedagogic and curricular designers in the development of systematic language programmes.

While each level describes a proficiency level that builds on the previous level, and the uppermost level is indicative of the highest mastery of language, it is not a 'threshold' in the same manner as a threshold concept. In other words, certain aspects of proficiency at a C2 level (i.e." can understand with ease virtually everything heard or read" (Cambridge, 2011)), are not necessarily troublesome nor indicative of transformed ways of understanding.

While the CEFR and the threshold level framework are eminently useful for the design of language curricula, instruction and assessment, what this paper posits is that threshold concepts may in a different way have a role to play in understanding and facilitating second language development. Given that "experts often under-estimate task difficulty for novices" (Hattie and Yates, 2014, p.12), it may be pertinent to re-evaluate where difficulties lie for learners, and if this may vary across contexts.

\section{Active Second Language Use as a Threshold Concept for Some Learners}

Presently, Japanese university students come for an examination-focused pre-university system. In terms of second language learning, English is the central language learned. The focus of the examination system is on passive or receptive skills - reading and listening, understanding of grammar structures and vocabulary knowledge. There is less focus on language as a communicative act, due to both this exam focus and issues related to "Japanese teachers' difficulties using English in class" (Yanagi \& Baker, 2016, p. 261).

As such, although Japanese university students come to English language classes with a grounding in receptive skills (although it should be noted that on the Test of English for International Communication (TOEIC), an internationally recognized test of English for non-native speakers, Japanese test-takers ranked $40^{\text {th }}$ out of 48 countries in 2013 (Hongo, 2014)), they may in a sense be 'communication novices'. However, Japanese universities do 
not have the pressure of an external examination system and as such have more freedom in the creation of language curricula and pedagogic experimentation. Also, they are currently tasked with the development of learners who are "global human resources" (Yonezawa, 2014, p.37), a major component of which is seen to be communicative fluency in English and other foreign languages. The result is a much higher focus on communicative competence in many university language programmes.

This transition is not always smooth - many Japanese university students struggle with communicative language teaching environments. This may be unsurprising, given their prior learning environment. Researchers have provided a variety of other explanations for this difficulty in active communication for Japanese learners in another language - "shyness and fear of standing out (McVeigh 2015), a high context communication style (Ting-Toomey \& Chung, 2011) a hierarchical context (Meyer, 2014), uncertainty avoidance (Hofstede, 2017) collectivist perspectives where giving wrong answers can be viewed as upsetting the harmony of the class group, unfamiliarity with active participation in class" (Carson, 2017, in press). Others take a very culturally context specific approach to understanding this issue, such as Matsuoka, Matsumoto, Poole and Matsuoka (2014) who examine the impact of the Japanese concept of 'seken' (public eye), suggesting that 'language educators need to consider carefully the social context of the Japanese student language community when facilitating individuals' development of English language competence” (p.193).

While the above explanations for the difficulties Japanese university students have communicating in an EFL context are likely to some degree valid (particularly when viewed in a cumulative sense), can the idea of language use and communication as a threshold concept deepen or further the understanding of this issue? By examining communicative second language usage in this context against the criteria of a threshold concept, we can look towards answering this question.

\subsection{A Threshold Concept is Transformative}

Pre-university second language education in Japan occurs for 8 years, 2 in elementary education and 6 over the junior and senior high school periods. Given the focus of this education is largely on the reception of language, and discrete language elements, and that this is a critical period when young learners are developing understandings about what they are learning, it is likely that they are developing a specific relationship with this foreign language. This is a relationship with an object of study, a body of information, rather than with a communicative tool. If and when such learners are able to understand English as a communicative tool, and use it for authentic purposeful communication, both their relationship with the language and with communication will alter.

\subsection{A Threshold Concept is Probably Irreversible}

Once learners have understood and experienced English as means for communication, for wider communication and for access to knowledge than they cannot find without it, it is higher unlikely that this understanding will revert to conceptions of it as a body of information with discrete parts and rules to be understood. Learning a new word will now be 
driven by, not only language programme requirements, but also a desire to express an emotion or idea. Learning a new grammar item will expand communication range, retaining its newer purpose.

\subsection{A Threshold Concept is Integrative}

Communication in any language requires putting all the elements together - grammar, vocabulary, reading, writing, listening and speaking - into a single idea - using the language. Once this has happened all the elements do become integrated. A new vocabulary item is learned and used grammatically in reading, writing, listening and speaking. The act of learning this new item has a deeper, integrative purpose, no longer simply the passive learning of inert knowledge.

\subsection{A threshold Concept is Expansive}

A second language as an object, albeit one requiring occasional performance, remains a closed body of knowledge. Achieving communication in another language can open the door to further languages and more international possibilities. Communicating in another language provides a mirror to our own modes of communication, and other possible modes of communication. Communicating in English as a foreign language links learners with the global media, alternative sources of information (for university students this is very relevant, as English is the language of published research), alternative career aspirations and routes, and new avenues for relationships.

\subsection{A Threshold Concept is Troublesome.}

Moving from passive learning of the parts of a language to using it in an authentic manner and context undeniably brings with it affective issues. It also brings with it cognitive issues, such as the learners understanding of their relationship with the language in question. Words on a page need to become words in motion. Learning language items for retention and recall, versus learning for communication requires different learning materials and methodologies. Trying to communicate without the same 'body of words' as one possesses in the L1 requires new communication strategies - expressing ideas clearly with a smaller vocabulary requires significant effort.

Perhaps most fundamentally (in a contextually-bound sense), conceptualising the second language as a means for communication in a national context where it is not widely required or used, requires guidance and a pedagogy that informs such an understanding.

\section{Crossing the Communicative Threshold}

In this section, I provide an example of how a typical university class was re-framed to incorporate the understanding of communicative language use as a threshold concept for the student group in question, in order to move passive language learners to active language users. 
A year long English discussion class was offered at a small Japanese university where students were academically capable and interested, but largely passive in their learning. Much of their language education revolved around regular TOEIC testing, a language test that examines passive language knowledge, reinforcing their 'information only' relationship with English. The course was re-adjusted as follows to help them cross the communicative threshold.

For the initial weeks of the course, the discussion topics were given over to reflection on language learning itself. Student groups were asked to think about

- What are we/you trying to do with this language?

- What have you done so far?

- What is working not and not working? Why?

- Is communicating in English really difficult?

- Do you need/want it? Why?

Although reflection is more prevalent in classrooms today, it was very heavily weighted in this context, given the need to overcome cognitive conservatism (Chan, Ho \& Ku, 2011) the learners had about language learning. A five week period was devoted to this type of discussion and reflection, a large time allocation because of the consideration of communication as a difficult threshold concept the students needed to cross in order to fully develop as second language learners.

Within the classroom, a community of practice model was used to encourage legitimate peripheral participation (Wenger, 2006) - discussions were structured in such a way to allow all class members, regardless of language proficiency to participate in some way. This allows for the 'transformation' to have occurred already for some learners, and for it to be a more transitional or protracted process for others. At all times, the environment was designed to be authentically communicative, rather than asking students to participate in abstracted, decontextualised language use. A textbook was not used, and student groups were responsible for developing their own communication-need driven glossaries for the duration of the course.

Negative assessment washback was avoided, as was assessment that allowed for liminality. This meant assessing active communicatory participation and assessment that weighted improvement and effort (Hattie, 2012). By assessing effort, rather than only communicative fluency, students were encouraged to continue trying to work their way across the troublesome threshold of communicating, while exploiting the positive learning and motivation gains of effort justification (or the IKEA effect, Norton, Mochon \& Ariely, 2011). Self-assessment was also used in line with the reflective focus of the course.

Ultimately, this course did not result in a classroom full of fluent English speakers, but it did result in a classroom of learners who could communicate and wanted to communicate - with differing levels of depth and accuracy - in a second language. As one student wrote 
I could speak English many. I didn't speak Japanese during this class, I want to do language!

The ontological shift from learning language to doing language may be a necessary shift for successful language learning in certain EFL contexts. In such cases, changing the structure and goals of some language classes, as outlined here, while time-intensive in a short-term sense, may indeed be time-saving in terms of the learning gains, and the learning to follow.

\section{Conclusion}

Applying the criteria of a threshold concept to the context of communicative language use in the Japanese EFL context suggested that this is a useful conceptualization to further understanding the language journey of those in this context. It also can provide educators and curricular and instructional designers with useful knowledge for the improved development of such competence. Ideally, English education in Japan would be approached from an active language standpoint from students' early years in education. Were such a situation to occur, then communicating in English might not be a troublesome threshold concept. This would require large change in several areas - such as how English language education is designed from elementary to junior and senior highs schools onto third level, how English language educators are trained to teach and the language proficiency levels required of them in order to qualify for teaching licenses.

However, given the current state of affairs in Japanese education, where wide-ranging changes occur very slowly, communicating in English may remain a threshold concept. But this information is useful for university educators. Rather than becoming dismayed at perceived student unwillingness or inability to communicate in English, by better understanding their position, curricula that assist all to cross this threshold effectively can be created, resulting in a decreased number of students enrolled in English language courses who do not develop communicative competency and fall behind in the development of their potential.

Approaching communicative language teaching in institutions where it has not been the norm for learners can be done more effectively by asking some fundamental questions -

- Does your institution's second language curriculum provide a well-considered embedded pathway for moving from 'language learning' across the threshold to communicating comfortably in another language?

- Do curricula, instructional and assessment practices allow for liminality? Can a student in your institution succeed in your language programme without being an active communicator?

- Could learners become active communicators earlier if the approach towards having them communicate is more sensitive to their relationship with the language, to what is actually being asked of them, and just how difficult it is? 
This paper posits that second language use may be a threshold concept in certain contexts. This is a new perspective on threshold concepts, as it brings context and culture to the discussion of troublesome knowledge. Unlike opportunity cost or complex numbers, which seem to be threshold concepts for learners regardless of context, might it be the case that different educational contexts and structures, alongside culturally learned thinking and behaviours, can in fact, create (or remove) a level of difficulty within some learning items that render them troublesome?

\section{References}

Arnold, J. (Ed.) (1999). Affect in Language learning. Cambridge: Cambridge University Press.

Carson, L. (in press). Teaching Internationally for Internationalisation: Western Perspectives in an Eastern Context. In (eds.) Bizzell, B., Talbot, P. \& Kahila, R. Cultural Competencies and Educational Diplomacy in International Settings. Pennsylvania: IGI Global.

Chan, N. M., Ho, I. T., \& Ku, K. Y. L. (2011). Epistemic beliefs and critical thinking of Chinese students. Learning and Individual Differences, 21(1), 67-77. https://doi.org/10.1016/j.lindif.2010.11.001

Hattie, J. (2012). Visible learning for teachers: Maximizing impact on Learning. London: Routledge.

Hattie, J., \& Yates, G. (2014). Visible Learning and the Science of How We Learn. Oxon: Routledge.

Hofstede, G. (2017). Cultural Dimensions. Retrieved Mar 2, 2017 from https://geert-hofstede.com/cultural-dimensions.html

Hongo, J. (2014). Japan ranks 40 out of 48 countries in TOEIC scores. Retrieved Mar 21, 2017 from http://blogs.wsj.com/japanrealtime/2014/07/18/japan-ranks-40th-of-48-countries-in-toei c-scores/

Land, R. (2011). Multimedia Presentation: Threshold Concepts and Troublesome Knowledge. Retrieved from https://my.ohecampus.com/lens/home?locale=en_us

Land, R., Meyer, J.H.F., \& Smith, J. (2008). Threshold Concepts within the Disciplines. Rotterdam: Sense Publishers.

Matsuoka, R., Matsumoto, K., Poole, G., \& Matsuoka, M. (2014). Japanese university students' willingness to communicate in English: The serendipitous effect of oral presentations. Journal of Pan-Pacific Association of Applied Linguistics, 18(1), 193-218

McVeigh, B. J. (2015). Japanese higher education as myth. Oxon: Routledge. 
Meyer, E. (2014). The Culture Map: Breaking Through the Invisible Boundaries of Global Business. New York: Public Affairs.

Meyer, J. H. F., \& Land, R. (Eds.). (2013). Overcoming barriers to student understanding: threshold concepts and troublesome knowledge. London, UK: Routledge.

Norton, M., Mochon, D., \& Ariely, D. (2011). When labor leads to love: The IKEA effect. Journal of Consumer Psychology, 22, 453-460. https://doi.org/10.1016/j.jcps.2011.08.002

O’Brien, M. (2008). Threshold Concepts for University Teaching and Learning. In (Eds.) Land, R., J.H.F. Meyer \& J. Smith. Threshold Concepts within the Disciplines. Rotterdam: Sense Publishers.

Orsini-Jones, M. (2008). Troublesome Language Knowledge: Identifying threshold concepts in grammar learning. In R. Land, J.H.F. Meyer \& J. Smith).Threshold Concepts within the disciplines. Rotterdam: Sense Publishers.

Perkins, D. (2012). Constructivism and Troublesome Knowledge. In J. H. F. Meyer \& R. Land (Eds.) Overcoming barriers to student understanding: threshold concepts and troublesome knowledge (pp. 33-47). London UK Routledge.

Using the CEFR: Principles of Good Practice. (2011). Retrieved Mar 2017 from: http://www.cambridgeenglish.org/images/126011-using-cefr-principles-of-good-practice .pdf

Smith-Christmas, C. (2017). 'Is it really for talking?: the implications of associating a minority language with the school. Language, Culture. https://doi.org/10.1080/07908318.2016.1230619

Ting-Toomey, S., \& Chung. L. C. (2011). Understanding Intercultural Communication. Oxon: Oxford University Press.

Wenger, E. (2006). Communities of practice: A brief introduction. Retrieved from http://www.vpit.ualberta.ca/cop/doc/wenger.doc

Yanagi, M., \& Baker, A. A. (2016). Challenges Experiences by Japanese Studies with Oral Communication Skills in Australian Universities. TESOL Journal, 7(3), 621-644. https://doi.org/10.1002/tesj.229

Yonezawa, A. (2014). Japan's Challenge of Fostering "Global Human Resources": Policy Debates and Practices. Japan Labor Review, 11(2), 37 -52.

\section{Copyright Disclaimer}

Copyright for this article is retained by the author(s), with first publication rights granted to the journal.

This is an open-access article distributed under the terms and conditions of the Creative Commons Attribution license (http://creativecommons.org/licenses/by/3.0/). 